\title{
Beneficial effect of genistein on lowering blood pressure and kidney toxicity in fructose-fed hypertensive rats
}

\author{
Nallasamy Palanisamy* and Anuradha C. Venkataraman \\ Department of Biochemistry and Biotechnology, Faculty of Science, Annamalai University, Annamalai Nagar 608 002, \\ Tamil Nadu, India \\ (Submitted 29 September 2011 - Final revision received 11 July 2012 - Accepted 31 July 2012 - First published online 21 September 2012)
}

\begin{abstract}
The study evaluates the effects of genistein on blood pressure (BP) and ultrastructural changes in kidney of fructose-fed hypertensive rats. Male Wistar rats were fed a diet containing $60 \%$ starch or $60 \%$ fructose as the source of carbohydrate. After $15 \mathrm{~d}$, rats in each dietary group were divided into two groups and were treated with either genistein ( $1 \mathrm{mg} / \mathrm{kg}$ per d) in dimethylsulfoxide (DMSO) or $30 \%$ DMSO alone. $\mathrm{BP}$, pressor mechanisms, protein kinase C-BII (PKC- $\beta \mathrm{II}$ ) expression, endothelial NO synthase (eNOS) expression and renal ultrastructural changes were evaluated after $60 \mathrm{~d}$. Fructose-fed rats displayed significant elevation in BP and heart rate. Significant increase in plasma angiotensin-converting enzyme (ACE) activity, alterations in renal lipid profile, nitrite and kallikrein activity, enhanced expression of membrane-associated PKC-BII and decreased expression of eNOS were observed in them. Histology and electron microscopic studies showed structural changes in the kidney. Genistein administration lowered BP, restored ACE, PKC- $\beta$ II and eNOS expression and preserved renal ultrastructural integrity. These findings demonstrate that genistein has effects on eNOS activity in renal cells, leading to eNOS activation and NO synthesis. These effects could have been mediated by activation of PKC- $\beta$ II. The observed benefits of genistein make it a promising candidate for therapy of diabetic kidney disease.
\end{abstract}

Key words: Blood pressure: Endothelial nitric oxide synthase: Fructose: Genistein: Nitric oxide

The fructose-fed rat mimics the human metabolic syndrome in which a constellation of abnormalities such as glucose intolerance, insulin resistance, dyslipidaemia, hyperinsulinaemia and hypertension are described ${ }^{(1)}$. These risk factors predispose to type 2 diabetes, CVD and renal disease. Renal hypertrophy, arteriolopathy, glomerular hypertension, cortical vasoconstriction and oxidative damage are the pathological findings observed in fructose-fed rats ${ }^{(2)}$. The rise in blood pressure (BP) in this model has been related to defects in vasodilatory mechanisms such as impaired $\mathrm{NO}^{\circ}$ production due to decreased endothelial NO synthase (eNOS) activity, activation of selective isoforms of protein kinase C (PKC) and downregulation of the renal kallikrein-kinin system $^{(3-5)}$

Genistein, a phyto-esterogen with isoflavone structure, is found in a wide variety of plant-derived foods, in particular in soyabean. Genistein exerts an anti-diabetic effect by improving glucose and lipid metabolism in type 2 diabetic subjects $^{(6)}$. A study has demonstrated the beneficial effects of soya isoflavones on kidney damage induced by nephrotoxins $^{(7)}$. Interestingly, we found that genistein improves insulin sensitivity and restores renal function in fructose-fed rats ${ }^{(8)}$. However, there is a lack of data that directly relate the improvement of $\mathrm{BP}$ and renoprotective effect of genistein in the insulin-resistant state. The present study was therefore designed to investigate the effects of genistein on $\mathrm{BP}$, related pressor mechanisms like plasma angiotensin-converting enzyme (ACE), $\mathrm{NO}^{\circ}$ and kallikrein and the expression of eNOS and PKC- $\beta$ II in fructose-fed hypertensive rats. In addition, the effects of genistein on lipid profile and kidney structural changes were studied.

\section{Methods}

\section{Chemicals}

Anti-PKC- $\beta$ II antibody was purchased from Sigma Chemicals, while anti-eNOS (Sigma) antibody was obtained as a generous gift from Dr Z. Serfozo, Department of Experimental Zoology, Hungarian Academy of Sciences, Tihany, Hungary. Genistein (Sigma) was obtained as a generous gift from Dr T. Szkudelski, Department of Animal Physiology and Biochemistry, August Cieszkowski University of Agriculture, Poland. All chemicals and solvents used for the study were purchased from SISCO Research Laboratories Private Limited.

Abbreviations: ACE, angiotensin-converting enzyme; BP, blood pressure; eNOS, endothelial nitric oxide synthase; PBS-T, PBS containing 0.05\% Tween-20; PKC, protein kinase C; RMMCH, Rajah Muthiah Medical College and Hospital. 


\section{Animals}

Adult male Wistar rats of body weight 150-160g were obtained from the Central Animal House, Rajah Muthiah Medical College and Hospital (RMMCH), Annamalai University. They were housed in a well-ventilated animal room under controlled conditions on a $12 \mathrm{~h}$ light $-12 \mathrm{~h}$ dark cycle. Animals received the standard pellet diet (Karnataka State Agro Corporation Limited, Agro Feeds Division) and water ad libitum. The experimental procedures were done according to the guidelines of the Committee for the Purpose of Control and Supervision of Experiments on Animals and were approved by the Institutional Ethical Committee of Animal Care, RMMCH, Annamalai University, Annamalai Nagar, India (no. 160/1999/CPCSEA/425).

\section{Experimental design}

After the acclimatisation period of $7 \mathrm{~d}$, the rats were divided into four groups of twelve rats each as follows: (1) Group 1 rats were fed the control diet containing $60 \%$ maize starch, $20 \%$ protein, $0.7 \%$ methionine, $5 \%$ ground nut oil, $10 \cdot 6 \%$ wheat bran, $3.5 \%$ salt mixture and $0.2 \%$ vitamin mixture and given the vehicle $(0.5 \mathrm{ml} 30 \%$ dimethylsulfoxide/d) by oral administration for $60 \mathrm{~d}$, (2) Group 2 rats were fed the high-fructose diet, which had similar composition to that of the control diet, except that starch was replaced by fructose, and administered dimethylsulfoxide for $60 \mathrm{~d}$, as described for rats in Group 1; (3) Group 3 rats were fed the high-fructose diet and administered genistein $(1 \mathrm{mg} / \mathrm{kg}$ per $\mathrm{d}$ in $0.5 \mathrm{ml}$ dimethylsulfoxide) from day 16 until day 60 by oral administration and (4) Group 4 rats were fed the control diet and administered genistein from the 16th day till the 60th day of the experimental period, as described for Group 3.

On day 60 , the animals ( $n$ 6) were kept in individual metabolism cages, and $24 \mathrm{~h}$ urine samples were collected in sealed beakers with added preservative and killed by cervical dislocation after administering anaesthesia (ketamine hydrochloride $30 \mathrm{mg} / \mathrm{kg}$, intramuscular). The abdomen was cut open and kidneys were dissected, washed in ice-cold saline and weighed. Portions of kidney were cut and homogenised in $0 \cdot 1-\mathrm{M}$ Tris- $\mathrm{HCl}$ buffer ( $\mathrm{pH} 7 \cdot 4$ ) and used for the assays.

\section{Blood pressure measurement}

$\mathrm{BP}$ was measured in conscious rats $(n$ 6) by the indirect tail-cuff method using a fully automatic BP analyser (Doc-NIBP200A, BIO PAC Systems). The rats were kept in a constant temperature $\left(32^{\circ} \mathrm{C}\right)$ chamber for $30 \mathrm{~min}$ and then placed in a rat holder. A total of eight $\mathrm{BP}$ measurements were carried out in each animal. An average of six such readings was taken as the individual (systolic/diastolic) $\mathrm{BP}$, neglecting the maximal and minimal values. The sum of the diastolic pressure and one-third of the pulse pressure was taken as the mean arterial pressure.

\section{Biochemical analysis}

Total nitrite (nitrate + nitrite) as a measure of $\mathrm{NO}^{\cdot(9)}$, plasma ACE activity ${ }^{(10)}$ and the activity of kallikrein ${ }^{(11)}$ were measured. Plasma and renal tissue cholesterol, TAG and NEFA were measured by methods outlined elsewhere ${ }^{(12)}$.

\section{Immunoblot analysis of protein kinase $C-\beta / l$ and endothelial nitric oxide synthase}

The cytosol and membrane fractions of the kidney were prepared as follows: $500 \mathrm{mg}$ of kidney were homogenised in $5 \mathrm{ml}$ of ice-cold extraction buffer ( $40 \mathrm{~mm}$-sucrose, $50 \mathrm{mm-HEPES,} 280 \mathrm{~mm}-\mathrm{NaCl}$ and $20 \mathrm{~mm}-\mathrm{NaOH}$ and protease inhibitor cocktail; Sigma Chemical Company). The homogenate was centrifuged at $1000 \boldsymbol{g}$ for $5 \mathrm{~min}$ at $4^{\circ} \mathrm{C}$. The supernatant obtained was used as the total cell lysate fraction. The total cell lysate was centrifuged again at $100000 \mathbf{g}$ for $60 \mathrm{~min}$ at $4{ }^{\circ} \mathrm{C}$. The supernatant obtained was used as the cytosolic fraction, while the pellet was resuspended in ice-cold lysis buffer (50 mm-HEPES, $480 \mathrm{~mm}-\mathrm{NaCl}, 20 \mathrm{~mm}-\mathrm{NaOH}$ and $2 \%$ SDS) with protease inhibitor cocktail and centrifuged at $100000 \mathrm{~g}$ for $60 \mathrm{~min}$ at $4^{\circ} \mathrm{C}$. The pellet was discarded and the supernatant was used as the membrane fraction. Protein concentration was measured by the method of Lowry et $a l .{ }^{(13)}$. The sample $(100 \mu \mathrm{g}$ protein) was solubilised in $2 \times$ Laemmli sample buffer. The total cell lysate (for eNOS expression) and the cytoplasmic and membrane proteins (for PKC- $\beta I I$ expression) were subjected to electrophoresis in SDS-PAGE gel (6\% for eNOS and 8\% for PKC-BII) and blotted onto nitrocellulose membranes in a transferring buffer at $80 \mathrm{~mA}$ in a transfer apparatus for $1 \mathrm{~h}$ and $30 \mathrm{~min}$. The membranes were then pre-incubated in the blocking buffer (PBS containing 0.05\% Tween-20 (PBS-T)) and 5\% non-fat dried milk for $2 \mathrm{~h}$ at room temperature and then probed with rabbit polyclonal anti-eNOS primary antibody (1:750 dilution) or mouse monoclonal anti-PKC- $\beta$ II primary antibody (1:1000 dilution) overnight at $4^{\circ} \mathrm{C}$ and washed with PBS-T thrice and incubated with either goat anti-rabbit secondary antibody (1:4000) or goat anti-mouse secondary antibody (1:5000 dilution) (Genei) for $2 \mathrm{~h}$ and again washed with PBS-T thrice. Antigen-antibody complexes were detected using a chemiluminescence kit (Thermo Fisher Scientific, Inc.) and quantified by Image J, a public domain Java image processing software (Wayne Rasband, National Institutes of Health). $\beta$-Actin was used as the house keeping internal control. The data for test proteins are normalised with corresponding $\beta$-actin values and are presented as arbitrary units.

\section{Histology}

A portion of kidney tissue removed from each group was fixed in $8 \%$ neutral formalin, dried and embedded in paraffin wax. Sections of $3-5 \mathrm{~mm}$ were cut, processed and stained with periodic acid-Schiff stain. The slides were examined under a light microscope.

\section{Transmission electron microscopic examination of kidney}

A portion of renal tissue was cut into small pieces and prefixed in $2.5 \%$ glutaraldehyde $(0.2 \mathrm{~mol} / 1$ cacodylate buffer, 
Table 1. Body and kidney weight, systolic and diastolic blood pressure, mean arterial pressure (MAP), heart rate, angiotensin-converting enzyme (ACE), kallikrein and nitrite in plasma and urine of experimental rats

(Mean values and standard deviations of six animals)

\begin{tabular}{|c|c|c|c|c|c|c|c|c|}
\hline \multirow[b]{2}{*}{ Parameters } & \multicolumn{2}{|c|}{ CON } & \multicolumn{2}{|c|}{ FRU } & \multicolumn{2}{|c|}{$\mathrm{FRU}+\mathrm{GEN}$} & \multicolumn{2}{|c|}{$\mathrm{CON}+\mathrm{GEN}$} \\
\hline & Mean & SD & Mean & SD & Mean & SD & Mean & SD \\
\hline Body weight (g) & $182 \cdot 9$ & $12 \cdot 4$ & $226 \cdot 6^{\star}$ & 14.7 & $189 \cdot 3 \dagger$ & 11.9 & $186 \cdot 6$ & 11.0 \\
\hline Kidney weight (g) & 1.95 & 0.13 & $2 \cdot 24^{\star}$ & 0.14 & $1.75 \dagger$ & 0.11 & 1.91 & $0 \cdot 11$ \\
\hline Systolic pressure (mmHg) & $115 \cdot 6$ & 8.9 & $189 \cdot 2^{*}$ & $12 \cdot 5$ & $128 \cdot 64 \dagger$ & $8 \cdot 12$ & $113 \cdot 21$ & 8.36 \\
\hline Diastolic pressure (mmHg) & $72 \cdot 1$ & 5.5 & $94.9^{*}$ & $6 \cdot 2$ & $79 \cdot 37 \dagger$ & $5 \cdot 01$ & $68 \cdot 16$ & 5.03 \\
\hline MAP $(\mathrm{mmHg})$ & 86.6 & $6 \cdot 7$ & $126 \cdot 3^{\star}$ & $8 \cdot 3$ & $95.79 \dagger$ & 6.04 & $83 \cdot 18$ & $6 \cdot 14$ \\
\hline Heart rate (beats per min) & 343 & $26 \cdot 3$ & $379^{\star}$ & 25 & $344.51 \dagger$ & $21 \cdot 7$ & $342 \cdot 32$ & $25 \cdot 29$ \\
\hline \multicolumn{9}{|l|}{ Plasma } \\
\hline ACE (nkat/l) & $123 \cdot 50$ & $8 \cdot 33$ & $239.00^{*}$ & $14 \cdot 00$ & $141 \cdot 84 \dagger$ & 8.83 & $123 \cdot 00$ & $7 \cdot 16$ \\
\hline Kallikrein ( $\mu \mathrm{mol}$ of substrate converted/min per litres of plasma) & $5 \cdot 27$ & 0.35 & $4 \cdot 35^{\star}$ & 0.25 & $6.01 \dagger$ & 0.37 & $5 \cdot 29$ & 0.31 \\
\hline Nitrite $(\mu \mathrm{mol} / \mathrm{l})$ & 11.83 & 0.90 & $8 \cdot 54^{\star}$ & 0.56 & $10 \cdot 0 \dagger$ & 0.63 & 11.83 & 0.87 \\
\hline \multicolumn{9}{|l|}{ Urine } \\
\hline Nitrite ( $\mu \mathrm{mol} / \mathrm{d}$ per $100 \mathrm{~g}$ body weight) & $2 \cdot 67$ & 0.20 & $1.73^{*}$ & 0.11 & $2 \cdot 30 \dagger$ & 0.14 & $2 \cdot 71$ & $0 \cdot 19$ \\
\hline
\end{tabular}

CON, control rats; FRU, fructose-fed rats; FRU + GEN, fructose + genistein (1 mg/kg body weight per d); CON + GEN, control + genistein (1 mg/kg body weight per d).

* Mean values were significantly different compared to control rats $(P<0.05$, Duncan's multiple range test).

† Mean values were significantly different compared to fructose-fed rats $(P<0.05$, Duncan's multiple range test).

$\mathrm{pH} 7 \cdot 4)$ for $4 \mathrm{~h}$ and then post-fixed in $1 \%$ buffered osmium tetroxide for $1 \mathrm{~h}$ and embedded in epoxyresin. Ultra-thin sections were stained with uranyl acetate and lead citrate, examined and photographed under a Philips-P201 transmission electron microscope (Koninklijke Philips Electronics).

\section{Statistical analysis}

Values are expressed as means and standard deviations. Data within the groups were analysed using one-way ANOVA followed by Duncan's multiple range test. A value of $P<0.05$ was considered statistically significant.

\section{Results}

\section{Blood pressure, nitrite, kallikrein and angiotensin- converting enzyme}

Table 1 presents body and kidney weight, systolic and diastolic BP, mean arterial pressure, heart rate, kallikrein, ACE and total nitrite values. Systolic and diastolic BP, mean arterial pressure, heart rate and ACE activity were significantly $(P<0.05)$ increased in fructose-fed rats. Kallikrein activity was lower by $21 \%$ and total nitrite by $38 \%$ in fructose-fed rats compared to control rats. Supplementation of genistein restored the levels, which were not significantly different from control rats.

\section{Plasma and kidney lipid content}

Fig. 1(a) and (b) represent the levels of plasma and kidney lipids, respectively, in experimental animals. Significant increases were observed in plasma cholesterol, TAG and NEFA in the fructose-fed rats (by 29,40 and $35 \%$, respectively). Genistein administration resulted in significant reductions in cholesterol, TAG and NEFA levels in fructosefed rats. Similarly, the levels of cholesterol, NEFA and TAG were significantly higher in the kidney of fructose-fed rats than in those fed the control diet (Fig. 1(b)). Genistein treatment of fructose-fed rats restored the levels of kidney lipids to near-normal values.
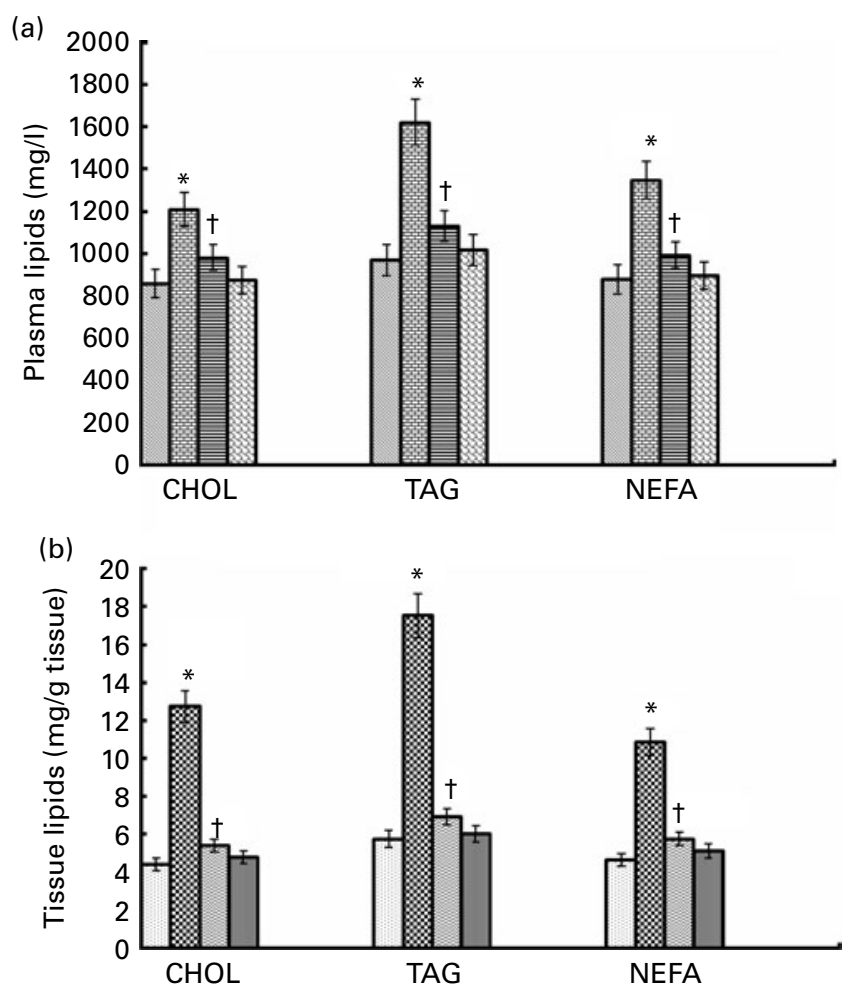

Fig. 1. (a) Plasma and (b) kidney lipid profile of experimental animals. CHOL, cholesterol. (a) ㄸ, Control rats (CON); 토, fructose-fed rats (FRU); E, fructose + genistein (1 mg/kg body weight per d) (FRU + GEN); ๘, control + genistein $(1 \mathrm{mg} / \mathrm{kg}$ body weight per d) (CON + GEN). (b) 匹, CON; 쁘, FRU; ᄃ, FRU + GEN; ㄷ, CON + GEN. * Mean values were significantly different compared to CON $(P<0.05$; ANOVA followed by Duncan's multiple range test). † Mean values were significantly different compared to FRU $(P<0.05$; ANOVA followed by Duncan's multiple range test). 
(a)

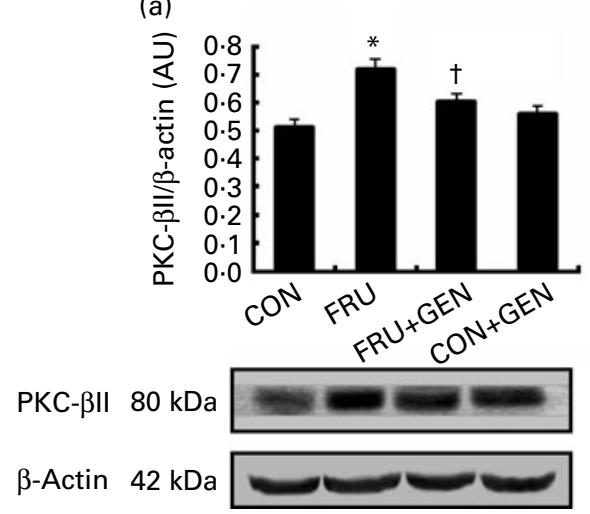

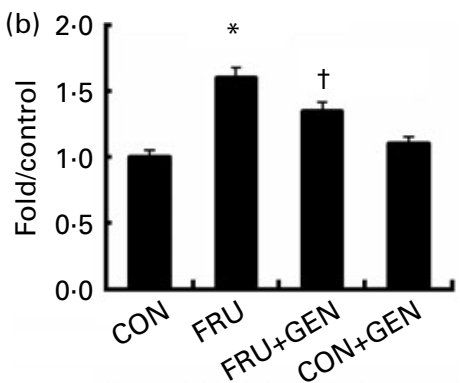

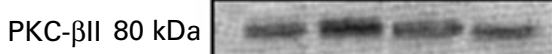

Fig. 2. Representative immunoblot of protein kinase C- $\beta$ II (PKC- $\beta$ II) isoenzyme in kidney (a) cytosol and (b) membrane and representative densitometry analysis of Western blots a and b, respectively. Values are expressed as relative intensity and means of six independent experiments, and standard deviations represented by vertical bars. CON, control rats; FRU, fructose-fed rats; FRU + GEN, fructose + genistein (1 mg/kg body weight per d); CON + GEN, control + genistein $(1 \mathrm{mg} / \mathrm{kg}$ body weight per $\mathrm{d})$. ${ }^{*}$ Values were significantly different compared to CON $(P<0.05$; ANOVA followed by Duncan's multiple range test). $\dagger$ Values were significantly different compared to FRU $(P<0.05$; ANOVA followed by Duncan's multiple range test). AU, arbitrary units.

\section{Protein kinase C- $\beta / l$ and endothelial nitric oxide synthase expression}

Fig. 2(a) and (b) depict the expression of PKC- $\beta$ II in the cytosolic and membrane fractions, respectively, and give the densitometry data of the respective blots. Significant increase in PKC- $\beta$ II expression was observed in both the fractions in the fructose-fed group compared to the control group. Expression was significantly reduced in the fructosefed genistein-treated group, as compared to the genistein untreated fructose-fed group.

Fig. 3 depicts a representative immunoblot showing eNOS expression in the kidney of experimental rats, together with a bar plot giving the results of densitometry analysis of the protein bands. The eNOS expression was significantly lower in the fructose-fed group, as compared to the control group. Protein expression was similar in all other groups.

\section{Structural studies}

Fig. 4(a)-(d) represents the kidney sections of animals analysed by periodic acid-Schiff staining $(40 \times$ magnification). Under a light microscope, kidneys from fructose-fed animals showed glomerular hypertrophy, glomerular sclerosis and interstitial damage (Fig. 4(b)). Kidney sections from fructose + genistein-treated animals showed reduced pathological changes (Fig. 4(c)) compared to those observed in fructose-treated animals. Kidney sections from the control group and the control group treated with genistein showed normal glomerular and tubular histology (Fig. 4(a) and (d)).

Fig. 5 presents the transmission electron microscopic images showing renal architecture and podocyte foot processes of experimental animals. Podocyte and basement membrane from control (Fig. 5(a)) and control plus genistein (Fig. 5(d))treated groups show similar architecture. Fructose-fed rat kidney shows extensive disruption of podocytes and effacement. Arrows show basement membrane thickening and the presence of excess matrix proteins (Fig. 5(b)). Treatment with genistein significantly prevented these pathological structural changes (Fig. 5(c)). Podocytes and basement membrane appear normal in genistein-treated control animals.

\section{Discussion}

The fructose-fed rat is a well established model of the metabolic syndrome associated with renal dysfunction and hypertension $^{(14)}$. In the present study, fructose feeding caused deleterious effects on pressure-regulatory mechanisms and kidney structure. Several processes that contribute to a rise in BP such as sympathetic nervous system overactivation,
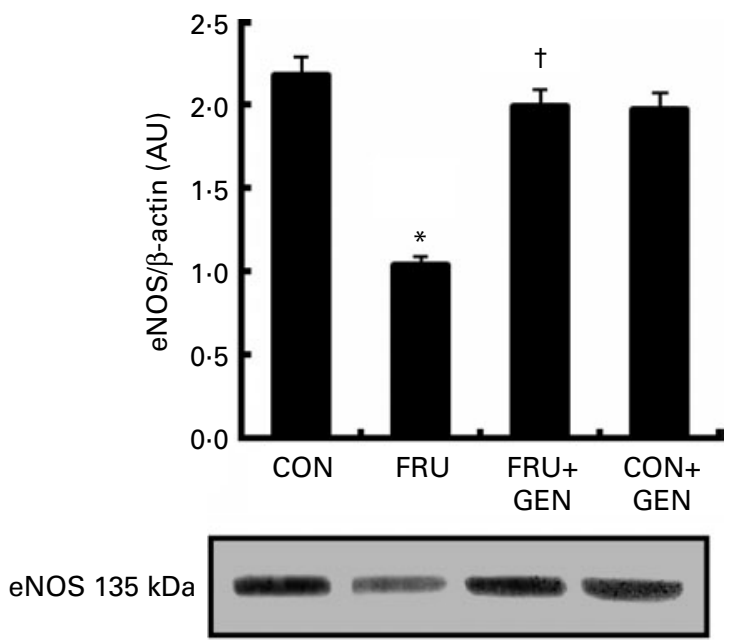

$\beta$-Actin $42 \mathrm{kDa}$

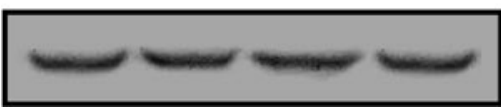

Fig. 3. Representative immunoblot of endothelial nitric oxide synthase (eNOS) in kidney cell lysate and representative densitometry analysis of the bands. Values are expressed as relative intensity and means of six independent experiments, and standard deviations represented by vertical bars. $\mathrm{CON}$, control rats; FRU, fructose-fed rats; FRU + GEN, fructose + genistein $(1 \mathrm{mg} / \mathrm{kg}$ body weight per $\mathrm{d})$; CON + GEN, control + genistein $(1 \mathrm{mg} / \mathrm{kg}$ body weight per d). * Mean values were significantly different compared to CON $(P<0.05$; ANOVA followed by Duncan's multiple range test). $†$ Mean values were significantly different compared to FRU $(P<0.05$; ANOVA followed by Duncan's multiple range test). AU, arbitrary units. 

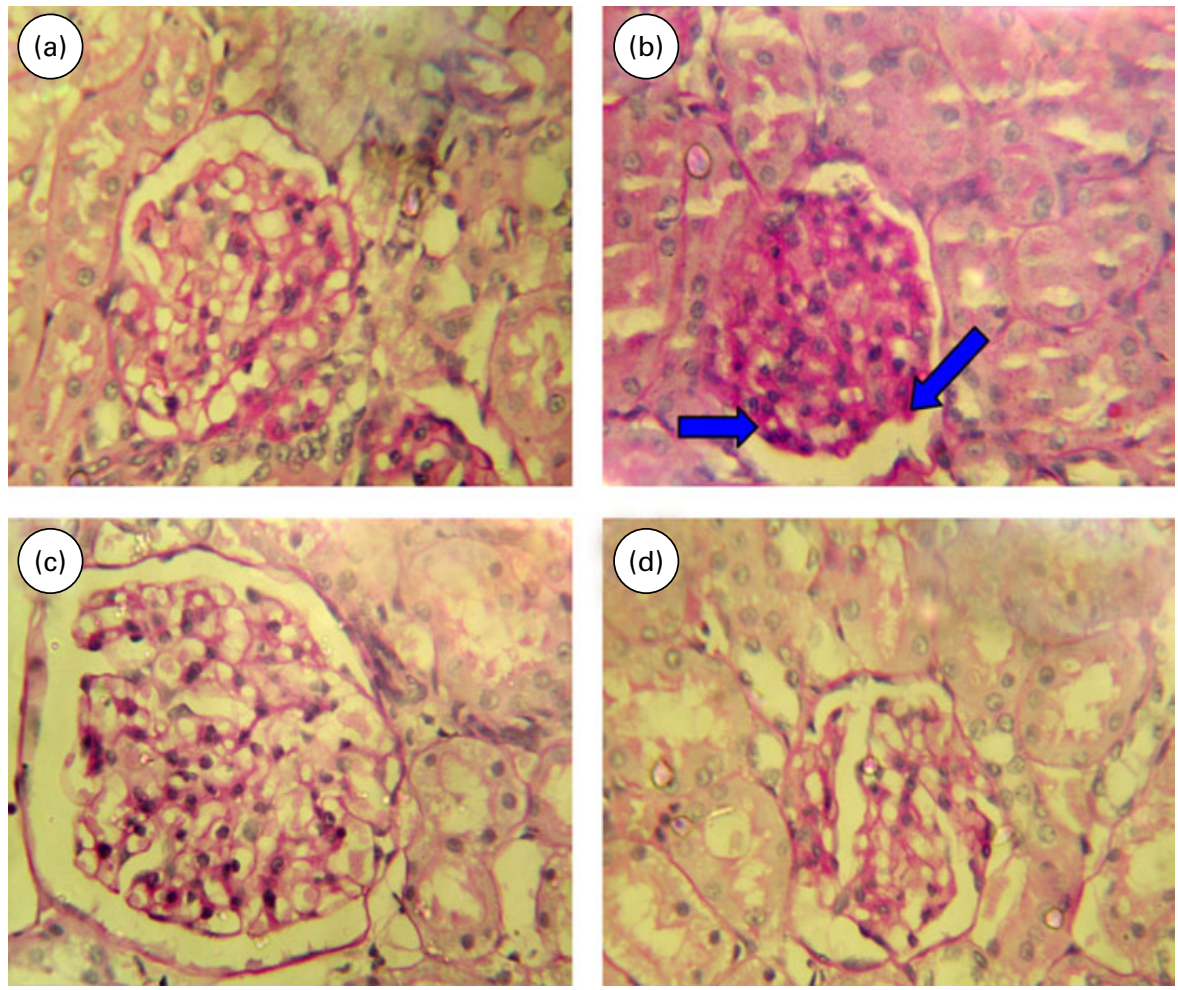

Fig. 4. Representative micrographs of kidney tissue stained with periodic acid-Schiff from (a) control rats, (b) fructose-fed rats, (c) fructose + genistein-treated rats $(1 \mathrm{mg} / \mathrm{kg}$ body weight per $\mathrm{d})$ and (d) control + genistein-treated rats $(1 \mathrm{mg} / \mathrm{kg}$ body weight per d). (a-d) Magnification $400 \times$. (A colour version of this figure can be found online at http://www.journals.cambridge.org/bjn).

increased production of vasoconstrictors, defects in $\mathrm{NO}$ and increased formation of reactive oxygen species are reported in fructose-fed rats. It has been suggested that elevation of BP in this model is a sequence of hyperinsulinaemia, as insulin induces inappropriate $\mathrm{Na}$ retention, activation of the sympathetic nervous system and the renin-angiotensin system $^{(15,16)}$

ACE catalyses the formation of angiotensin II, the aldosterone-stimulating peptide, from angiotensin I. A previous study has shown that genistein decreased ACE expression dose-dependently in rat aortic endothelial cells via oestrogen receptors ${ }^{(17)}$. The antihypertensive and beneficial cardiovascular effects of genistein have been reported by Montenegro et $a l{ }^{(18)}$. The observed mechanisms were inhibition of plasma ACE, both in vivo and in vitro, reduction in the hypertensive response to angiotensin I and increase in the hypotensive response to bradykinin.

The kallikrein enzyme acts on kininogen substrates to release kinins, which bind to the bradykinin $\mathrm{B} 2$ receptors, and cause vasodilatation by $\mathrm{NO}^{\circ}$ production. Defects in vasodilatory mechanism in fructose-fed rats have been found to be associated with decreased NO production ${ }^{(19)}$ and infusion of sodium nitroprusside, an $\mathrm{NO}$ donor, improves insulin sensitivity in fructose-fed rats ${ }^{(20)}$. Vascular protective effects and regulation of eNOS by genistein have been observed in animal and human studies ${ }^{(21,22)}$. Genistein enhances eNOS gene transcription and protein synthesis in spontaneously hypertensive rats ${ }^{(23)}$. Stimulation of NO release and reduction in peripheral vascular resistance by genistein could influence $\mathrm{BP}$ and the distribution of blood flow in this model.

Several studies reveal that insulin could regulate the expression of $e N O S$ gene through activation of phosphatidyl inositol 3 kinase (PI3) kinase ${ }^{(24)}$. We earlier showed that genistein promotes insulin action in high fructose-fed rats by assessing the homeostasis model assessment values (control rats, 9.39; fructose-fed rats, 42.89; fructose + genistein $(1 \mathrm{mg} / \mathrm{kg}$ body weight per $\mathrm{d}), 11 \cdot 16$; control + genistein ( $1 \mathrm{mg} / \mathrm{kg}$ body weight per d), 8.87), although we did not measure PI3 kinase activation by genistein. Although genistein is a known tyrosine kinase inhibitor, studies have shown that at physiological (low dose) concentration, it induces tyrosine phosphorylation of insulin-like growth factor 1 receptor and insulin receptor substrate-1 in cancer cell lines ${ }^{(25)}$. We suggest that genistein by its insulin sensitivity effects might activate eNOS expression partly via the activation of PI3 kinase.

Podocytes are visceral epithelial cells that share the characteristics of both a mesenchymal and an epithelial cell. The podocyte slit diaphragm is the final filtration barrier in the glomerular endothelial basement membrane-podocyte interface. Podocytopathy is present early in the natural history of diabetic nephropathy and plays an important role in micro- and macro-albuminuria. Broadening of foot processes with eventual effacement and dysfunction of podocytes were observed in fructose-fed rats. In addition, podocyte abnormalities were mitigated by genistein treatment. 

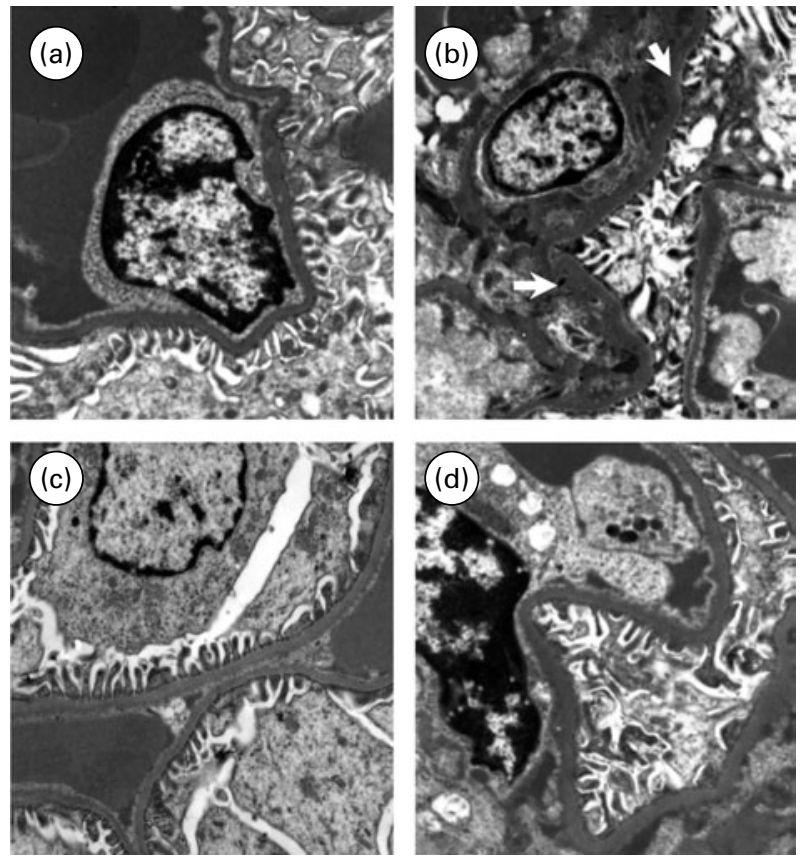

Fig. 5. (a-d) Transmission electron microscopic examination of rat kidney ( $\times 10000)$. (a) An electron micrograph from a control rat. Regularly arranged podocyte foot processes with normal basement membrane are observed. (b) An electron micrograph from a fructose-fed rat. Abnormal foot processes effacement, podocyte appear broadened, basement membrane thickening and extensive deposition of matrix proteins (blue arrows) are seen. (c) An electron micrograph from a genistein-treated fructose-fed rat shows basement membrane within normal limits; some podocyte foot processes appear broadened. (d) Electron micrograph from a genistein-treated control rat shows normal structure of podocytes and basement membrane.

A large body of evidence has demonstrated that oxidative stress is an important mediator of fructose-induced membrane and structural damage of kidney ${ }^{(26)}$. Genistein might have recovered the kidney from structural alterations by its antioxidative capacity. This has been reported earlier by us using haematoxylin and eosin staining ${ }^{(8)}$. Periodic acid-Schiff staining not only shows glycogen content, but also detects structural deterioration characterised by disorganisation of contractile and cytoskeletal proteins. Genistein was found to improve the overall renal structure.

Elevated circulating lipids may contribute to renal disease progression $^{(27)}$. In contention with this, we observed marked increases in lipid levels in both plasma and kidney of fructose-fed rats. Lipids bind to extracellular matrix molecules and are peroxidised, thereby increasing reactive oxygen species production ${ }^{(28)}$. These processes affect the structure and function of the kidney. Genistein has been shown to be a PPARy agonist to improve lipid metabolism in murine RAW 264.7 cells and in obese Zucker rats ${ }^{(29)}$. The lipidlowering effect of genistein observed in the present study could be one of the mechanisms for its renoprotective action.

Hyperglycaemia and angiotensin II are potent inducers of PKC- $\beta$ II activation ${ }^{(30)}$. Activated PKC- $\beta$ II translocates to the membrane and triggers the production of endothelin 1 , a vasoactive peptide that causes endothelial dysfunction, vascular smooth muscle contraction and proliferation, leading to a rise in $\mathrm{BP}^{(31)}$. Fructose-fed rats exhibited hyperglycaemia and enhanced ACE activity in the present study. Lowering of glucose and inhibition of ACE by genistein could have contributed to the reduction in PKC- $\beta$ II activation and BP. The BP-lowering effect of genistein has been shown already in stroke-prone spontaneously hypertensive rats ${ }^{(32)}$, ovariectomised hypertensive rats $^{(33)}$ and in spontaneously hypertensive rats ${ }^{(34)}$. Important vascular effects of genistein include an increase in inducible NO synthase activity, inhibition of platelet aggregation and arterial vasorelaxation ${ }^{(35)}$ and prevention of vascular alterations ${ }^{(36)}$.

In conclusion, the inhibitory effect on ACE and PKC- $\beta I I$ activation and increased availability of kinins and NO could be the contributory mechanism for the BP-lowering effect and renoprotection by genistein. It remains to be seen whether the insulin sensitivity effect of genistein may underlie the renoprotective action.

\section{Acknowledgements}

The financial support in the form of a Senior Research Fellowship to Dr N. P. from the Indian Council of Medical Research, New Delhi is gratefully acknowledged. A. C. V. designed the study protocol and edited the draft manuscript; N. P. conducted the experiments, analysed the data and wrote the draft of the manuscript. All authors read and approved the final manuscript. The authors declare no conflict of interest.

\section{References}

1. Reaven GM (1994) Syndrome X: six years later. J Int Med 736, $13-22$

2. Sanchez-Lozada LG, Tapia E, Jimenez A, et al. (2007) Fructose-induced metabolic syndrome is associated with glomerular hypertension and renal microvascular damage in rats. Am J Physiol Renal Physiol 292, 423-429.

3. Haller H, Baur E, Quass P, et al. (1995) High glucose concentrations and protein kinase $\mathrm{C}$ isoforms in vascular smooth muscle cells. Kidney Int 47, 1057-1067.

4. Rajasekar P, Palanisamy N \& Anuradha CV (2007) Increase in nitric oxide and reductions in blood pressure, protein kinase C beta II and oxidative stress by L-carnitine: a study in the fructose-fed hypertensive rat. Clin Exp Hypertens 29, $517-530$

5. Nishimoto Y, Tomida T, Matsui H, et al. (2002) Decrease in renal medullary endothelial nitric oxide synthase of fructose-fed, salt-sensitive hypertensive rats. Hypertension 40, 190-194.

6. Park SA, Choi MS, Cho SY, et al. (2006) Genistein and daidzein modulate hepatic glucose and lipid regulating enzyme activities in C57BL/KsJ-db/db mice. Life Sci 79, 1207-1213.

7. Kojima T, Uesugi T, Toda T, et al. (2002) Hypolipidemic action of the soybean isoflavones genistein and genistin in glomerulonephritic rats. Lipids 37, 261-265.

8. Palanisamy N, Viswanathan P \& Anuradha CV (2008) Effect of genistein, a soy isoflavone, on whole body insulin sensitivity and renal damage induced by a high-fructose diet. Ren Fail 30, 645-654.

9. Rock E, Astier C, Lab C, et al. (1995) Magnesium deficiency in rats induces a rise in plasma nitric oxide. Magnes Res $\mathbf{8}$ $237-242$ 
10. Holmquist B, Bünning P \& Riordan JF (1979) A continuous spectrophotometric assay for angiotensin converting enzyme. Anal Biochem 95, 540-548.

11. Trautschold I, Werle E \& Schweitzer G (1974) Methods in Enzymatic Analysis, vol. 2, New York, NY: Academic Press, Inc.

12. Raghuramulu N, Madhavan Nair K \& Kalyanasundaram K (2003) A Manual of Laboratory Techniques, 2nd ed. Hyderabad: National Institute of Nutrition Press.

13. Lowry OH, Rosebrough NJ, Farr AL, et al. (1951) Protein measurement with the Folin phenol reagent. $J$ Biol Chem 193, 265-275.

14. Vasdev S, Gill V, Parai S, et al. (2002) Dietary vitamin E and C supplementation prevents fructose induced hypertension in rats. Mol Cell Biochem 241, 107-114.

15. Bhanot S, Salh BS, Verma S, et al. (1999) In vivo regulation of protein-serine kinases by insulin in skeletal muscle of fructose-hypertensive rats. Am J Physiol 277, 299-307.

16. Vasdev S, Longerich L \& Gill V (2004) Prevention of fructoseinduced hypertension by dietary vitamins. Clin Biochem 37, 1-9.

17. Xu YY, Yang C \& Li SN (2006) Effects of genistein on angiotensin-converting enzyme in rats. Life Sci 79, $828-837$

18. Montenegro MF, Pessa LR \& Tanus-Santos JE (2009) Isoflavone genistein inhibits the angiotensin-converting enzyme and alters the vascular responses to angiotensin I and bradykinin. Eur J Pharmacol 607, 173-177.

19. Kamata K \& Yamashita K (1999) Insulin resistance and impaired endothelium-dependent relaxation in fructosehypertensive rats. Am J Hypertens 9, 370-376.

20. Oshida Y, Tachi Y, Morishita Y, et al. (2000) Nitric oxide decreases insulin resistance induced by high-fructose feeding. Horm Metab Res 32, 339-342.

21. Mahn K, Borras C, Knock GA, et al. (2005) Dietary soy isoflavone induced increases in antioxidant and eNOS gene expression lead to improved endothelial function and reduced blood pressure in vivo. FASEB J 19, 1755-1757.

22. Räthel TR, Leikert JF, Vollmar AM, et al. (2005) The soy isoflavone genistein induces a late but sustained activation of the endothelial nitric oxide-synthase system in vitro. $\mathrm{BrJ}$ Pharmacol 144, 394-399.

23. Si H \& Liu D (2008) Genistein, a soy phytoestrogen, upregulates the expression of human endothelial nitric oxide synthase and lowers blood pressure in spontaneously hypertensive rats. J Nutr 138, 297-304.

24. Kuboki K, Jiang ZY, Takahara N, et al. (2000) Regulation of endothelial constitutive nitric oxide synthase gene expression in endothelial cells and in vivo: a specific vascular action of insulin. Circulation 101, 676-681.

25. Chen WF \& Wong MS (2004) Genistein enhances insulin-like growth factor signaling pathway in human breast cancer (MCF-7) cells. J Clin Endocrinol Metab 89, 2351-2359.

26. Choi HN, Park YH, Kim JH, et al. (2011) Renoprotective and antioxidant effects of Saururus chinensis Baill in rats fed a high-fructose diet. Nutr Res Pract 5, 365-369.

27. Vaziri ND \& Norris K (2011) Lipid disorders and their relevance to outcomes in chronic kidney disease. Blood Purif 31, 189-196.

28. Morena M, Patrier L, Jaussent I, et al. (2011) Reduced glomerular filtration rate, inflammation and HDL cholesterol as main determinants of superoxide production in nondialysis chronic kidney disease patients. Free Radic Res $\mathbf{4 5}$, 735-745.

29. Mezei O, Banz WJ, Steger RW, et al. (2003) Soy isoflavones exert antidiabetic and hypolipidemic effects through the PPAR pathways in obese Zucker rats and murine RAW 264.7 cells. J Nutr 133, 1238-1243.

30. Koya D \& King GL (1998) Protein kinase C activation and the development of diabetic complications. Diabetes $\mathbf{4 7}$, 859-866.

31. Pfaff IL \& Vallon V (2002) Protein kinase C beta isoenzymes in diabetic kidneys and their relation to nephroprotective actions of the ACE inhibitor lisinopril. Kidney Blood Press Res 25, 329-340.

32. Xu JW, Ikeda K \& Yamori Y (2004) Genistein inhibits expressions of NADPH oxidase p22 phox and angiotensin II type 1 receptor in aortic endothelial cells from strokeprone spontaneously hypertensive rats. Hypertens Res 27, 675-683.

33. Nevala R, Lassila M, Finckenberg P, et al. (2002) Genistein treatment reduces arterial contractions by inhibiting tyrosine kinases in ovariectomized hypertensive rats. Eur J Pharmacol 452, 87-96.

34. Vera R, Galisteo M, Villar IC, et al. (2005) Soy isoflavones improve endothelial function in spontaneously hypertensive rats in an estrogen-independent manner: role of nitric-oxide synthase, superoxide, and cyclooxygenase metabolites. J Pharmacol Exp Ther 314, 1300-1309.

35. Mishra SK, Abbot SE, Choudhury Z, et al. (2000) Endothelium-dependent relaxation of rat aorta and main pulmonary artery by the phytoestrogens genistein and daidzein. Cardiovasc Res 46, 539-546.

36. Bermejo A, Zarzuelo A \& Duarte J (2003) In vivo vascular effects of genistein on a rat model of septic shock induced by lipopolysaccharide. J Cardiovasc Pharmacol 42, 329-338. 